\title{
(t)
}

\section{ABEPSS 2009-2010: ESTÁGIO, PESQUISA E CONSOLIDAÇÃO INSTITUCIONAL}

ABEPSS 2009-2010: training, research and institutional consolidation

\section{Elaine Rossetti Behring'}

\section{INTRODUÇÃO}

A Associação Brasileira de Ensino e Pesquisa de Serviço Social (Abepss) tem sido um pilar fundamental da organização político-profissional do Serviço Social brasileiro, como parte do que designamos a partir dos anos 90 como Projeto Ético-Político profissional. Em que pese suas orientações e documentos não terem força de lei, a Abepss conta com forte legitimidade política e respeito acadêmico, o que pudemos constatar na vivência da Gestão 20092010. Essa referência foi construída nos seus 65 anos de história e tem permitido direcionar a formação profissional em Serviço Social no Brasil, ainda que num ambiente bastante adverso ao projeto preconizado em seu documento mais importante das últimas décadas, as Diretrizes Curriculares de 1996 (ABEPSS, 1996), de onde decorrem suas demais orientações.

O presente artigo relata e analisa, brevemente, o período - janeiro de 2009 a janeiro de 2010 - em que tivemos a honra de estar

${ }^{1}$ Professora Adjunta do Departamento de Serviço Social da Faculdade de Serviço Social da Uerj, Pesquisadora do CNPq e Ex-Presidente da Abepss (Gestão 2009-2010).E-mail: <elan.rosbeh@uol.com. br>. 


\section{à frente de um coletivo ${ }^{2}$ democrático, corajoso, combativo e sufi- cientemente coeso para impulsionar a Abepss em torno de algu- mas prioridades, eventos marcantes - a exemplo da homenagem ao Congresso da Virada, o XIII CBAS e o XII Enpess - e de lutas im- portantes, dentre as quais destacamos a resistência à graduação a distância e a luta pelas 30 horas, ao lado do Conjunto CFESS-Cress e da Enesso. O fio condutor do nosso relato e a análise, de minha inteira responsabilidade, é o Relatório Final de Gestão apresenta- do na Assembleia da Abepss, realizada no âmbito do XII Encontro}

\footnotetext{
${ }^{2}$ Composição da Diretoria eleita da Abepss - Gestão 2009-2010 (por ocasião da eleição na Assembleia de São Luís em dezembro de 2008. Outros nomes foram agregados depois): Diretoria Nacional - Presidente: Elaine Rossetti Behring (Uerj); Coordenadora Nacional de Graduação: Sâmya Rodrigues Ramos (Uern); Coordenadora Nacional da Pós-Graduação: Yolanda Demetrio Aparecido Guerra (UFRJ); Secretária: Alba Tereza Barroso de Castro (Uerj); Tesoureiro: Maurílio Castro de Matos (Uerj); Coordenador Nacional de Relações Internacionais - Carlos Montaño (UFRJ); Representante Estudantil Nacional de Pós-Graduação: Rosângela Oliveira Gonzaga de Almeida (UFRJ); Representante Estudantil Nacional de Pós-Graduação (Suplente): Sandra Oliveira Teixeira (Uerj); Representante Estudantil Nacional de Graduação: Maria Aparecida Milanez Cavalcante (UFPI); Representante Estudantil Nacional de Graduação (Suplente): Sheila Dias Almeida (UFRJ); Suplente Docente da Executiva Nacional: Marlene Teixeira Rodrigues (UnB); Suplente Docente da Executiva Nacional: Maria Lúcia Duriguetto (UFJF); Diretoria Regional Norte - Vice-Presidente: Lília Penha Viana Silva (UFMA); Coordenadora de Graduação: Nádia Socorro Fialho Nascimento (UFPA); Coordenadora de Pós-Graduação: Lúcia Cristina dos Santos Rosa (UFPI); Representante de Supervisores de Campo: Andréia Carla Santana Everton (UFMA); Representante Estudantil de Graduação: Luciana Aires Rosa (UFPA); Representante Estudantil de Graduação (Suplente): Sanyse Campos Sabino (UFMA); Representante Estudantil de Pós-Graduação: Silvana Compton Barroso (Ufam); Representante Estudantil de Pós-Graduação (Suplente): Doracy Moraes de Souza (UFPA); Suplente Docente: Heloísa Helena Corrêa da Silva (Ufam); Diretoria Regional Nordeste - Vice-Presidente: Josiane Soares Santos (UFS); Coordenação de Graduação: Nailsa Maria Souza Araújo (UFS); Coordenação Regional de Pós-Graduação: Maria Norma Âlcantara Brandão de Holanda (Ufal) Representante Discente de Graduação: Maria Clariça Ribeiro Guimarães (Uern); Representante Discente de Graduação: Dilma Franclin (Suplente) (Ucsal); Representante Discente de Pós-Graduação: Erlenice Sobral do Vale (UFPE); Suplente Docente: Maria da Conceição Almeida de Vasconcelos (UFS); Representante dos Supervisores de Campo de Estágio: Albany Mendonça Silva (UFS); Diretoria Regional Sul 1 - Vice-Presidente: Alzira Maria Baptista Lewgoy (PUC-RS); Coordenação de Graduação: Dunia Comerlatto (Unochapecó); Coordenação de Pós-Graduação: Cássia Maria Carloto (UEL); Suplente da Diretoria: Ana Lúcia Suárez Maciel (PUC-RS); Representante Discente de Graduação: Fernanda Tomé B. da Silva (PUC-RS); Diretoria Regional Centro-Oeste - Vice-Presidente Regional: Regina Sueli de Sousa (UCG); Coordenadora de Graduação: Eleusa Bitemgiana Ribeiro (UCG); Coordenador de Pós-Graduação: Perci Coelho (UnB); Suplente Docente: Maria José de Faria Viana (UCG); Representante Estudantil de Graduação: Marília Sampaio Teixeira Pinto (UCB); Representante Estudantil de Pós-Graduação: Jamila Zgiet Rodrigues (UnB); Suplente de Representante Estudantil de Graduação: Viviane Carla Germano de Paula (UCG); Suplente de Representante Estudantil de Pós-Graduação: Elizabeth dos Santos Moura Batista (UCG); Representante de Supervisores: Patrícia Basílio Perez Estábile (UCG); Diretoria Regional Leste - Vice-Presidente: Cláudia Mônica Santos (UFJF); Coordenação de Pós-Graduação: Cleusa Santos (UFRJ); Coordenadora de Graduação: Maria Helena E. Abreu (Ufes); Suplente: Tatiana Rangel Reis (UFJF); Diretoria Regional Sul 2 - Vice-Presidente: Maria Liduína de Oliveira e Silva (Unifesp); Coordenação de Graduação: Cirlene Aparecida Hilário da Silva Oliveira (Unesp); Coordenadora de Pós-Graduação: Maria Lúcia Barroco (PUC-SP); Representante Discente da Graduação: Carina Moreira Medeiros (PUC-SP); Representante Discente da Pós-Graduação: Rosemerie dos Santos (PUC-SP).
} 
Nacional de Pesquisadores em Serviço Social (Uerj - dezembro de 2010). Nosso objetivo é oferecer a este número histórico da Revista Temporalis, que comemora os 65 anos da Abepss, um registro desse breve e marcante momento da vida da entidade, que evidentemente se confunde com a dos militantes que lhe imprimiram movimento, em que me incluo.

A Gestão 2009-2010 da Abepss orientou-se pelos seguintes princípios programáticos e que se traduziram em ações e prioridades num Plano de Trabalho, definido na primeira Reunião Ampliada da Diretoria da Abepss $^{3}$ (março de 2009): 1. Defesa da universidade pública, gratuita, democrática, laica e socialmente referenciada, articulando ensino, pesquisa e extensão; 2 . Luta contra a precarização e aligeiramento do ensino, em especial contra cursos de graduação, mestrado e doutorado a distância e mestrados profissionalizantes; 3. Articulação entre graduação e pós-graduação; 4. Defesa do trabalho docente com dignidade e contra o "produtivismo" e competitividade em detrimento da qualidade; 5 . Defesa do projeto ético-político profissional, compreendendo a importância da sinergia entre formação e exercício profissionais; 6 . Articulação com as entidades da categoria - Conjunto CFESS/Cress e Enesso; 7. Articulação com o Andes-SN e as lutas em defesa da educação pública e gratuita; 8. Articulação com os movimentos sociais para a resistência à barbarização da vida social e contra a socialização dos custos da crise do capital para os trabalhadores; 9. Garantia da gestão democrática e ética dos recursos e patrimônio da Abepss. Desde o princípio da gestão, definimos um plano de ação ousado com base nesses princípios orientadores, mas com modestas, porém claras, prioridades dentro de alguns eixos. Esse foi um caminho necessário, considerando que uma gestão de dois anos é curta e exige uma grande agilidade política para que tenha alguma efetividade e visibilidade. À medida que desenvolvermos os eixos, apontaremos as prioridades e o que se realizou, sendo que é possível avaliar hoje

\footnotetext{
${ }^{3}$ A Reunião Ampliada compôs-se da Diretoria Nacional e das Regionais, incluindo os Coordenadores de Graduação e Pós-Graduação Regionais (às expensas da Abepss), e aqueles que puderam vir com recursos das UFAs, das Regionais ou próprios. Trata-se de uma estratégia de democratização das decisões, considerando as dificuldades financeiras da entidade e o tamanho da Diretoria da Abepss (Nacional e Regionais).
} 
a correção dessa decisão coletiva, que nos permitiu não perder o foco e assegurar aquelas prioridades total ou parcialmente.

\section{A CONSOLIDAÇÃO INSTITUCIONAL DA ABEPSS}

Embora a entidade tenha sido fundada em 1946 como uma associação de escolas, a antiga Abess, seu processo de consolidação institucional não acompanhou sua grande legitimidade político-acadêmica. Explico-me: mesmo tendo sido reestruturada como Abepss a partir de 1998, definindo-se já naquele momento a necessidade de superar uma dinâmica itinerante crônica, que implicava na perda ou dispersão de documentos históricos e em dificuldades institucionais elementares com certidões, situação fiscal, filiações, comunicação e outros procedimentos importantes para a vida cotidiana da Abepss, chegamos em 2009 com parte dessas questões ainda em presença. Enfrentou-se essa condição na gestão 19992000, a partir da instalação de uma sede fixa em Brasília, cedida pelo CFESS, mas que não teve solução de continuidade na gestão subsequente. Decidimos, então, que essa seria uma prioridade do nosso trabalho, entendendo que a ação política se sustenta em condições objetivas, sendo absolutamente fundamental superar a insegurança material e institucional da nossa histórica entidade voltada à formação profissional. O primeiro passo foi retomar o projeto da sede em Brasília, capital do país, fixando também todos os procedimentos cartoriais, bancários, fiscais e institucionais. Para tanto, com a intermediação do Departamento de Serviço Social e do Decanato de Pesquisa e Pós-Graduação ${ }^{4}$ da UnB, demos início a um processo de negociação com a Reitoria da Universidade de Brasília, tendo em vista a cessão de um espaço físico naquela universidade pública, processo que foi concluído festivamente com a inauguração da nova sede em setembro de 2009, no endereço que consta no website da Abepss. Ao lado disso, mantivemos a Se-

\footnotetext{
${ }^{4}$ O Decanato de Pesquisa e Pós-Graduação (DPP) da Universidade de Brasília é gerido, desde 2009, pela Prof. Dra. Denise Bomtempo Birche de Carvalho, que já foi membro da Diretoria da Abepss, na qualidade de Coordenadora Nacional de Pós-Graduação (Gestão 1998 -2000), e teve um papel decisivo nesta negociação, ao lado de Rosa Stein e Ivanete Boschetti, do SER-UnB.
} 
cretária Executiva da Abepss - Maryluce Gomes ${ }^{5}$ - resguardando a memória administrativa recente da entidade, e contratamos uma assessoria contábil, que atualizou os registros contábeis, fiscais e cartoriais. Com esses passos, pudemos garantir junto à instituição bancária procedimentos virtuais mais modernos de cobrança de anuidades das escolas e individuais, bem como de acompanhamento das contas da Abepss, o que facilitou enormemente o processo de gestão. Todos os documentos e equipamentos da Abepss foram enviados para Brasília. Adquirimos novos equipamentos, tendo em vista esse processo de modernização da entidade. Os móveis e um computador foram cedidos pelo Grupo de Estudos e Pesquisas em Seguridade Social e Trabalho (Gesst) e pelo SER-UnB à Abepss. Outra questão foi reaberta concomitantemente: o resgate dos documentos históricos da Abepss que estavam na PUC-SP, com a manifestação daquela universidade de não mais guardar as cerca de 70 caixas de documentos, que estavam em seu cuidado desde a gestão 2000-2002 da Abepss. Assim, a entidade voltou a estar reunida plenamente após anos de dispersão, criando-se as condições para um tratamento sistemático do seu importante acervo de 65 anos de história, tarefa que não conseguimos avançar ainda na nossa gestão, mas que vem sendo assumida pela atual direção.

Esse movimento de modernização e profissionalização da entidade facilitou as iniciativas da Diretoria da Abepss quanto à comunicação, filiações e captação de recursos. Quanto à comunicação, inicialmente criamos o Blog da Abepss 2009-2010, enquanto o website era reformulado, numa perspectiva de tornar-se mais ágil e leve. Quando este último entrou em operação, produzido e alimentado por um profissional da área, tiramos o blog do ar, já que sua missão estava cumprida: manter os filiados, a categoria e a sociedade em geral informados dos passos e posições da Abepss. O website passou a ser nossa principal via de comunicação e informação, ainda que utilizássemos as redes de mails da Diretoria, Redes Sociais e a lista de contatos da Abepss para posicionamentos que exigissem uma divulgação rápida - e, vale dizer, foram muitos esses momen-

${ }^{5}$ Cabe uma nota de agradecimento público a nossa Secretária Administrativa Nacional que se mudou de São Luís para Brasília e vem dando uma contribuição importante para a vida da Abepss. 
tos, numa conjuntura dura e exigente, especialmente no campo da educação. Quanto às filiações, vale observar o quadro abaixo:

\begin{tabular}{|l|c|c|}
\hline \multicolumn{1}{|c|}{ ABEPSS } & 2007 - 2008 & $\mathbf{2 0 0 9}$-2010 \\
\hline Unidades de formação acadêmica (UFAs) filiadas & 92 & 95 \\
\hline Sócios Individuais & 93 & 284 \\
\hline Pré-Filiadas & - & 3 \\
\hline Cursos de Pós-Graduação & - & 2 \\
\hline Filiações em Processo & - & 2 \\
\hline UFAs em dia (10/2008 e 10/2009) & 55 & 50 \\
\hline
\end{tabular}

O quadro é revelador do crescimento das filiações individuais, fruto das bancas da Abepss nos eventos nacionais e regionais e dos intensos esforços regionais. Houve um levíssimo crescimento das filiações institucionais. Criamos, como se pode observar no quadro, a figura das UFAs Pré-Filiadas, considerando o crescimento das UFAs públicas (em menor número, mas significativo) e privadas, em maior número, em consonância com a política de incentivo à educação como mercadoria em curso no país. A ideia aqui foi aproximar essas instituições da Abepss, ainda que sem obrigações e direitos (ABEPSS, 2009) $)^{6}$, mas assegurando uma proximidade político-acadêmica até cumprirem os requisitos estatutários para a filiação, tendo em vista produzir repercussões em seus projetos pedagógicos. Na nossa gestão tivemos adesões a essa forma de participação na Abepss, o que vem se consolidando desde então. Incrementamos também a filiação dos cursos de pós-graduação, mas compreendendo que muitos deles já são filiados por meio das UFAs. Chama atenção o número de UFAs em atraso com a Abepss, o que tem sido uma constante e exige uma atenção da Secretaria, com apoio na Sede, e especialmente o acompanhamento das Diretorias Regionais.

Essa situação de crônica falta de recursos vem demandando estratégias de captação de recursos, que foram desencadeadas para a

${ }^{6}$ Conferir a Resolução de Pré-Filiação em ABEPSS (2009a). 
sustentação da ação política da Abepss. Nesse sentido, firmamos um convênio com o CFESS em torno da implementação do Plano de Lutas em Defesa do Trabalho e da Formação e Contra a Precarização do Ensino Superior, construído no âmbito do Conjunto CFESS-Cress e conduzido por um Grupo de Trabalho constituído pelo CFESS, um Cress de cada região, a Abepss e a Enesso. Dentro do Plano de Lutas encontrava-se a perspectiva de elaborar a Política Nacional de Estágio como um mecanismo de resistência à precarização da formação profissional, como veremos adiante. Portanto, esse convênio assegurou as iniciativas necessárias para essa prioridade central da gestão, destinando recursos para as Oficinas Regionais e Nacional de Graduação e Seminário Nacional de Pós-Graduação e Pesquisa da Abepss, no final de 2009 (UFRJ). Captamos recursos também junto ao Fenepas, assegurando ações em torno da formação em saúde em todos os eventos em que houve participação ou organização da Abepss, e complementando os recursos para outras ações, a exemplo dos eventos nacionais em 2009 e 2010 e da participação da Abepss no evento em comemoração ao Congresso da Virada. Encaminhamos o projeto do XII Enpess para agências de fomento e recebemos recursos da Capes e do CNPq para o maior evento de pesquisa da área, que se realizou no final de 2010 na Uerj.

\section{A DEFESA DAS DIRETRIZES DA ABEPSS: RESISTÊNCIA À PRECARIZAÇÃO E CRIAÇÃO DA PNE}

Em que pese um conjunto de iniciativas da gestão quanto à graduação, não há dúvidas de que engendramos nossos maiores e meIhores esforços para adensar e melhor qualificar a concepção de estágio supervisionado nas Diretrizes Curriculares, criando um documento orientador de fôlego sobre a forma e o conteúdo do estágio curricular em Serviço Social denominado Política Nacional de Estágio da Associação Brasileira de Ensino e Pesquisa em Serviço Social - Abepss (ABEPSS, 2009b). Evidentemente, essa foi uma decisão política balizada por algumas reflexões e fatos, já que inúmeras outras questões referentes às diretrizes mereceriam a formula- 
ção de estratégias específicas, a exemplo dos dilemas na formação sobre a relação entre Serviço Social e trabalho ou a relação entre Serviço Social e questão social, dentre outras questões que foram reveladas pela pesquisa realizada pela Abepss durante as gestões 2005-2006 e 2007-20087. No entanto, definimos fortalecer a implementação das Diretrizes pela via do Estágio Supervisionado, cujos dilemas também foram revelados pela referida pesquisa.

Quem viveu a história da formulação das Diretrizes vai lembrar que o estágio supervisionado não foi o debate mais quente daquele início dos anos 90 e requisitava há algum tempo um debate mais sistemático, considerando seu lugar estratégico na formação como uma espécie de disciplina síntese, e partindo do pressuposto de que o ensino do trabalho profissional é uma dimensão transversal à formação. Por outro lado, em tempos de precarização da formação e da expansão lamentável da graduação à distância, e considerando que as Diretrizes do Ministério da Educação, apesar de terem desfigurado o projeto da Abepss, mantiveram a estrutura do estágio, este passou a ter um lugar ainda mais central na luta em defesa da formação profissional de qualidade. Assim, o Conjunto CFESS-Cress produziu uma importante resolução sobre o tema - a Resolução $\mathrm{N}^{\circ} 533$, de 2008 (CONSELHO FEDERAL DE SERVIÇO SOCIAL, 2008) -, e aprovou em seu Encontro Nacional uma moção dirigida à Abepss em prol da Política de Estágio.

Decidimos, então, assumir esse desafio, compreendendo sua importância naquele momento histórico. Esse processo, conduzido pela Coordenação Nacional e Coordenadores Regionais de Graduação, um Grupo de Trabalho Interno e um Grupo de Especialistas ${ }^{8}$ indicados por região, incrementou uma grande mobilização nacional envolvendo as UFAs, professores, estudantes e assistentes sociais, militantes do Conjunto CFESS-Cress e da Enesso, realizando-se oficinas locais, regionais e nacional em torno de um documento base

\footnotetext{
7 É importante registrar que a atual gestão 2011-2012 está formulando um projeto de Abepss itinerante em torno da qualificação dos projetos pedagógicos e melhor implementação das Diretrizes Curriculares da Abepss. Os principais resultados da Pesquisa da Abepss estão publicados especialmente na revista Temporalis 14 e num CD-room que foi distribuído pela Abepss para todas as UFAs em 2008. ${ }^{8}$ Grupo composto por: Yolanda Shirley (NO), lana Vasconcelos (NE), Alzira Lewgoy (SUL I), Ana Vasconcelos (LESTE), Valquíria Mariano (SUL II), Carmen Regina Paro (CO).
} 
elaborado pela gestão e que posteriormente foi transformado no documento final já citado. Foram cerca de 80 eventos durante 2009 para elaboração da PNE que contaram com a participação de 175 UFAs e 4.445 participantes contabilizados. Um balanço preliminar do impacto da PNE foi feito no XII Enpess, em que se ressaltou sua importância, mesmo sendo um documento recente, a exemplo do redirecionamento das políticas de estágio de várias UFAs e da criação de Fóruns de Supervisores em alguns estados, articulando UFAs e Cress. Mas sabemos que existem inúmeras mediações para tornar um documento orientador uma realidade e esse monitoramento será um desafio permanente. A PNE também se constituiu num argumento forte contra a banalização e precarização da formação profissional, já que os cursos a distância encontram dificuldades profundas para implementar o estágio com qualidade ${ }^{9}$, tal como preconiza o documento. Os cursos presenciais nas esferas privada e pública, com suas particularidades, também têm sido instigados a rever seus procedimentos. Esse é, em nossa opinião, talvez o legado principal desta gestão à categoria e à história da Abepss.

A PNE, como já apontado, foi parte do Plano de Lutas em Defesa do Trabalho e da Formação e Contra a Precarização do Ensino Superior onde estavam previstas várias ações que caberiam às entidades nacionais e regionais de Serviço Social. A Abepss participou de duas audiências com o MEC, ambas marcadas por uma forte tensão referente à graduação a distância. A Abepss esteve presente em audiências públicas e mobilizações nos estados onde estas se realizaram. Visitou algumas das universidades públicas que criaram cursos de Serviço Social, no sentido de consolidar a sua futura adesão à entidade. Articulou com reitorias de universidades públicas no sentido da criação de novos cursos. Deu entrevistas e

\footnotetext{
9 O documento base que deu origem à Campanha "Educação Não é Fast-Food: diga não à Graduação a distância em Serviço Social”, recém-proibida por força de uma liminar que caçou a liberdade de expressão em prol da livre iniciativa das forças de mercado, formulado ainda na nossa gestão junto com o CFESS e a Enesso, intitulado Sobre a Incompatibilidade entre Graduação a distância e Serviço Social (SOBRE A INCOMPATIBILIDADE..., 2011b), reúne um conjunto de denúncias apuradas pelos Conselhos Regionais sobre essa modalidade de ensino e destaca que o estágio aparece literalmente como o espaço onde estão presentes as situações mais graves e insólitas.
} 
produziu documentos importantes ${ }^{10}$, dos quais destacamos o texto Insumos para a crítica do Sistema Nacional de Avaliação da Graduação: contribuições da Abepss para o debate (ABEPSS, 2010a), que deu uma contribuição significativa para o debate do Enade, na perspectiva de pontuar elementos de diálogo com o movimento estudantil e qualificar a discussão e as estratégias para lidar com essa política institucional de avaliação frágil, individualista e estimuladora do ranking entre as UFAs. O link de Graduação no website da Abepss foi reestruturado na gestão e lá estão hoje todos os documentos de referência para os projetos pedagógicos das UFAs. Participamos do GT Trabalho e Formação, que montou a campanha "Educação não é Fast-Food: diga não à graduação a distância em Serviço Social", que iniciou em março de 2011, com fortes desdobramentos nacionais. Por fim, cabe apontar que a Abepss tomou a decisão política coletiva, após um intenso e democrático debate, de participar da indicação da Comissão de Área junto ao Ministério da Educação, não abrindo mão de tentar alguma ingerência institucional, mesmo reconhecendo que o Ministério da Educação tem sido ponta de lança do projeto produtivista e privatista, com pouca permeabilidade à guerra de posição. Mas cabe à associação acadêmica e científica da área forçar que a impermeabilidade à defesa da política de educação como política pública e direito seja manifestada e explicitada pelo MEC.

\section{PÓS-GRADUAÇÃO, PESQUISA E ESTRATÉGIAS COLETIVAS DE QUALIFICAÇÃO DO SERVIÇO SOCIAL NO BRASIL}

As iniciativas de resistência também se fizeram presentes no âmbito da pós-graduação e a principal delas, e que hoje busca consolidação, foi a criação dos Grupos Temáticos de Pesquisa (GTPs).

\footnotetext{
${ }^{10}$ Seguem algumas das manifestações mais importantes da gestão e que podem ser encontradas na página da Abepss: Manifesto conjunto Abepss/CFESS/Cress e Enesso contra o ensino a distância e pela qualidade do ensino presencial; Moção de repúdio à ação policial que invadiu a Faculdade de Serviço Social da UFRJ; Moção de apoio ao debate ao lançamento do livro Criminalização do Aborto, de autoria do Maurílio Matos; Nota Pública da Abepss sobre o Descredenciamento da Unitins; Carta de repúdio à atitude da Faminas que proibiu a divulgação de cartaz da semana do assistente social em virtude da fotografia de um casal homossexual; Carta Aberta aos estudantes e trabalhadores dos cursos de graduação a distância em serviço social no Brasil (com CFESS e Enesso).
} 
Como na PNE, foi construído um documento base articulado pela Coordenação Nacional de Pós-Graduação, com forte participação da Executiva Nacional da Abepss. Este foi discutido nas Oficinas Regionais e nos Programas de Pós-Graduação, e finalizado no Seminário Nacional de Pós-Graduação, ainda que a compreensão do documento seja claramente de que a pesquisa é uma dimensão da formação que atravessa seus níveis de graduação e pós-graduação. O documento A Abepss e o Fortalecimento da Pesquisa na Área de Serviço Social: a estratégia dos Grupos Temáticos de Pesquisa (GTPs) (ABEPSS, 2009c) percorreu o país num processo que culminou em 2010 nos colóquios fundadores dos sete primeiros GTPs, com a escolha de suas Comissões Coordenadoras que vêm dando prosseguimento a essa experiência. Os GTPs, a nosso ver, são potencialmente uma resposta a um ambiente acadêmico que estimula o individualismo e o que vem sendo chamado de fordismo acadêmico, coletivizando o processo de produção do conhecimento e estimulando a produção na área de uma perspectiva não produtivista. Estivemos preocupados em diferenciar produção de produtivismo, com o que a interlocução entre os pesquisadores por meio dos GTPs pode ser um campo de estímulo a novas práticas acadêmicas solidárias e que ao fim e ao cabo fortaleçam a área de conhecimento.

A Abepss acompanhou a revisão da ficha de avaliação dos Programas de Pós-Graduação e Critérios Qualis Periódicos e Qualis Livros. Estimulou o debate sobre o Serviço Social na pesquisa com a organização de um debate antológico, na mesa sobre ética, em pesquisa no Seminário Nacional de Pós-Graduação e Pesquisa e a publicação de um texto de referência sobre ética em pesquisa, da Prof. ${ }^{a}$ Lúcia Barroco, no website e na revista Temporalis 18. Demos continuidade às ações junto às representantes da área de Serviço Social no CNPq e na Capes, inclusive participando ativamente da articulação para a indicação de nomes para composição da Coordenação de área na Capes, tendo sido indicados pela Abepss: Berenice Rojas, Ana Cristina Vieira, Marina Maciel, Maria Inês Bravo e Raquel Raichellis ${ }^{11}$. Houve também o incentivo à mobilização dos alunos de

"Berenice Rojas Couto foi posteriormente escolhida para a representação de área na Capes e isso 
pós-graduação em Serviço Social e articulação com a ANPG e as APG, incluindo a participação no Encontro Nacional da ANPG.

Ainda no campo da pós-graduação, vale destacar a experiência do Curso de Especialização Serviço Social: direitos e competências profissionais, construído em parceria com o CFESS, o SER-UnB e o Cead-UnB, “[...] dentro de uma proposta de capacitação permanente dos profissionais, que vem sendo construída desde 1999, prevendo uma articulação entre as entidades nacionais" (CFESS; ABEPSS, 2011a). Esse curso envolveu 922 profissionais de todo o país, no seu início, 80 tutores e orientadores de monografias (mestres ou doutores) e exigiu um acompanhamento cotidiano da Executiva Nacional da Abepss, constituindo-se um GT CFESS-Abepss. Dentro dessa experiência foi organizado um livro com o mesmo título com todos os textos inéditos produzidos para esse curso, de mais de 700 páginas e que tem sido largamente utilizado nas várias esferas da formação profissional. É importante registrar que o curso foi totalmente construído com base nas Diretrizes Curriculares da Abepss. O curso foi realizado a distância, com poucos momentos presenciais (três, incluindo palestra de abertura, prova intermediária e defesa da monografia), o que nos deu ainda mais clareza e convicção sobre os limites dessa metodologia num curso de graduação, bem como das potencialidades da tecnologia como um complemento nos processos de formação. Concluíram o curso 648 cursistas, número que corresponde a $70,28 \%$ do total, o que pode ser considerado um bom resultado, considerando os altos índices de evasão nessa modalidade de ensino, reconhecido pelos técnicos que lidam com essa metodologia ${ }^{12}$. No entanto, a Plataforma do Curso se revelou como um espaço rico e quente de debates, sendo uma espécie de termômetro da categoria durante a sua duração. A Abepss esteve sempre presente na Plataforma e todos os comunicados da entidade foram postados naquele espaço.

foi um resultado da concentração das indicações dos programas sob a coordenação da Abepss e em articulação com os representantes de área na ocasião, Mariângela Belfiori Wanderley e Marilda lamamoto.

${ }^{12}$ Informações detalhadas sobre a realização do curso podem ser encontradas no documento disponível nas entidades (Abepss e CFESS), intitulado Relatório Final do Curso de Especialização Latu Sensu em Serviço Social: Direitos Sociais e Competências Profissionais (CFESS; ABEPSS, 2011a). 
Uma frente importante desta gestão, que também fez parte da formação continuada pós-graduada, ainda que não exclusivamente, foi a discussão da formação em saúde, na ordem do dia em função dos cursos a distância e das residências profissionais. Foram realizadas então as seguintes ações: constituição de um grupo na diretoria responsável pelo encaminhamento das discussões sobre saúde, pelos professores Maurílio Mattos, Cleusa Santos e Marlene Teixeira, e que contou com um grupo de apoio, radicado no Rio de Janeiro, composto pelas professoras Maria Inês Bravo e Ana Vasconcelos e pela Assistente Social Dra. Fátima Masson; manteve-se uma interlocução permanente com as representantes do CFESS na saúde, conselheira Rodriane Oliveira e Ruth Bittencourt, conselheira nacional de saúde (CNS); houve participação dos representantes da Abepss nas Reuniões do colegiado ampliado do Fórum Nacional de Educação das Profissões na Área de Saúde (FNEPAS) nos anos 2009 e 2010. Ocupou-se o espaço do Fórum das Entidades Nacionais dos Trabalhadores da Área da Saúde (Fentas) em 2009 e 2010, onde se dá a articulação entre as entidades para as reuniões do Conselho Nacional de Saúde, e que contava no final de 2010 com a participação de trinta e seis (36) entidades de representação de trabalhadores/as, em âmbito nacional, entre associações, sindicatos, federações e confederações e algumas outras organizações representativas de trabalhadores. Nesse contexto, a Abepss foi eleita para uma representação de suplência no Conselho Nacional de Saúde (CNS). Como se pode observar, essa foi uma atividade intensa na gestão e que também fortaleceu a articulação política com o CFESS no campo da saúde.

\section{OUTRAS DIMENSÕES DA GESTÃO 2009-2010}

Se a PNE e os GTPs foram as prioridades centrais da Gestão, outras dimensões, não menos importantes, também nos ocuparam no período. A primeira a ser citada é a Revista Temporalis, que vinha há algum tempo sendo publicada com dois números de atraso, comprometendo seu processo de indexação, e também requisitava mudanças importantes no seu projeto gráfico e editorial para 
adequar-se melhor aos critérios correntes. Como um periódico coletivo da área, conduzido pela sua entidade de formação, a pressão sobre a revista se acentuou nos últimos anos. Diante disso, a gestão tomou iniciativas importantes, mas não conseguimos atualizar sua periodicidade, com o que consideramos ter atingido nosso objetivo apenas parcialmente. Quais medidas foram tomadas? Modificamos seu projeto gráfico e editorial e publicamos três números da Revista neste novo formato, nitidamente mais moderno, mais adequado aos critérios de indexação e com uma proposta estética inovadora, inspirada nos grafites de rua ${ }^{13}$. Regularizamos o envio da Revista para as UFAs e sócios individuais, uma reivindicação forte dos associados. Reativamos o fluxo contínuo de artigos, aproveitamos artigos indicados pelo Enpess, dando continuidade a uma política acertada da gestão anterior e encomendamos artigos temáticos, dentro de uma política editorial definida pelo GT Temporalis constituído pela Diretoria da Abepss para esse fim. Por outro lado, garantimos nos eventos nacionais da Abepss ao longo da gestão, encontros dos editores de periódicos ligados às UFAs para a troca de experiências e incremento de estratégias coletivas de fortalecimento da área, em tempos de pressão sobre as publicaçõos e de concepções produtivistas que não se coadunam com a dinâmica do Serviço Social e mais amplamente das Ciências Humanas e Sociais. Portanto, essas reuniões foram momentos de resistência: ao invés da competição entre os periódicos, a troca e a construção de modos de lidar com esse ambiente hostil, a exemplo da construção de bancos de artigos e trocas entre revistas, e outras.

Dedicamo-nos também ao fortalecimento das relações internacionais da Abepss, com destaque para a Asociación Latinoamericana de Escuelas e Investigación en Trabajo Social (Alaeits) como instância articuladora do ensino e da pesquisa em Serviço Social na América Latina, naquele momento sob gestão brasileira, com Ana Elisabete Mota à frente. Nesse sentido, a Abepss apoiou e divulgou o $19^{\circ}$ Slaets, coordenando as atividades com a Direção da Alaeits, e exerceu seu papel dirigente e organizativo junto à delegação

${ }_{13}$ Projeto proposto por Márcia Carnaval, que tem capturado o ethos da categoria com muita sensibilidade traduzida em belas artes e projetos, onde se inclui a Temporalis. 
brasileira no Slaets e, sobretudo, na Assembleia da Alaeits. Destacamos ainda a participação da Abepss na Conferência Mundial de Serviço Social, em Hong Kong, em 2010. Neste evento a Abepss acompanhou uma Oficina sobre a Definição de Serviço Social da Federação Internacional dos Assistentes Sociais (Fits) e Associação Internacional de Escolas de Serviço Social (Aiets), expressando sua posição crítica em relação à definição atual. Colaboramos na panfletagem de texto alternativo de definição de Serviço Social produzido pelo CFESS. Acompanhamos o conjunto da Conferência, realizando contatos com o Serviço Social crítico na Escócia, África do Sul, Palestina, Grécia, Inglaterra e países da América Latina. Por fim, participamos da Assembleia da Aiets dando um longo e detaIhado informe sobre o Serviço Social no Brasil.

O XII Encontro Nacional de Pesquisadores, realizado na Uerj, em dezembro de 2010, e que teve como tema Crise do Capital e Produção do Conhecimento na Realidade Brasileira: pesquisa para quê, para quem e como? concluiu a gestão 2009-2010 e foi mais um marco importante, com as plenárias fundadoras dos Grupos Temáticos de Pesquisa. Houve debates polêmicos e de fôlego sobre a graduação, a pós-graduação, as relações internacionais e a formação em saúde, consolidando os colóquios como momentos fundamentais do Enpess, em continuidade ao que já vinha sendo implementado. Foi um Enpess marcado por momentos emocionantes: a homenagem a Nobuco Kameyama a quem dedicamos o evento e que veio a falecer pouco tempo depois; a conectividade com a cultura popular, por meio da homenagem a Noel Rosa na arte do evento e numa roda de samba memorável e que integrou todas e todos no meIhor do espírito carioca; o relançamento do livro O Estruturalismo e a Miséria da Razão, de Carlos Nelson Coutinho. Vale lembrar que estes dois últimos momentos foram realizados em parceria com o movimento docente da UERJ - a Asduerj. O XII Enpess contou com uma Comissão Organizadora composta pela executiva nacional e membros da Abepss Leste e da Faculdade de Serviço Social da Uerj que se reuniu desde o final de 2009 para assegurar a qualidade do evento. Além das conferências e colóquios, o XII Enpess mostrou o crescimento da produção na área. Foi o maior Enpess realizado até então em número de trabalhos enviados, aprovados e publicados: 
1682 enviados; 1293 aprovados; e previstos para apresentação: 913 orais, 165 pôsteres e 32 Mesas Temáticas Coordenadas. Estes números mostram como foi intensa a adesão ao XII Enpess, cuja realização foi um sucesso, apesar dos percalços que sempre existem na construção de um grande evento como esse.

\section{MAIS VALE O QUE SERÁ...}

Concluindo este texto-relato com pitadas de análise por minha conta e risco, sobre a Gestão 2009-2010 da Abepss, vale dizer, por fim, que fechamos a gestão com saldo positivo em caixa, o que foi importante para o grupo que veio na sequencia e, pensamos modestamente, com um saldo político e organizativo relevante, apesar de sempre ser aquém do desejo. Um diferencial na gestão foi a condução da sucessão: realizamos desde o início de 2010 um debate político consistente sobre a necessidade de dar continuidade a várias das políticas que iniciamos e sobre a construção de um processo sucessório democrático. Na verdade, nossa gestão assumiu a direção da Abepss sob forte pressão, circunstância que todas e todos que estiveram em São Luis em dezembro de 2008 devem lembrar. De nossa parte, já em março de 2010 iniciamos os diálogos internos para a construção da futura direção da Abepss, no sentido de evitar o vazio e a pressão. Houve um processo suave de convencimento, articulações nacionais para assegurar a legitimidade da futura direção, enfim, movimentos políticos decisivos para gerar uma situação confortável para a gestão que viria: esta que está em curso, que tem à frente a companheira Cláudia Mônica dos Santos, da UFJF, que se constituiu como referência no grupo pela excelente gestão na Abepss-Leste. Enfim, falando agora de um ponto de vista mais pessoal, embora tenha assumido a Presidência da Abepss num momento em que não havia planejado nem desejado este projeto, a Abepss e o coletivo qualificado e aguerrido, mas também divertido e solidário, me ganhou. Em março de 2009, após a Reunião Ampliada, eu já estava definitivamente seduzida pela grande política e exercitava plenamente aquela que foi uma frase da gestão: “[...] eu não ando só, só ando em boa companhia [...]" (VINÍCIUS DE MORAIS). 


\section{REFERÊNCIAS}

ABEPSS. A Abepss e o Fortalecimento da Pesquisa na Área de Serviço Social: a estratégia dos Grupos Temáticos de Pesquisa (GTPs). Brasília, 2009c. Disponível em: <http://www.Abepss.org.br/briefing/documentos/GTPs_Novembro_de_2009_Final.pdf $>$.

ABEPSS. Diretrizes gerais para o curso de Serviço Social (Com base no Currículo Mínimo aprovado em Assembléia Geral Extraordinária de 8 de novembro de 1996). Rio de Janeiro, nov. 1996. Disponível em: <http://www.abepss.org.br/briefing/documentos/Lei_de_Diretrizes_Curriculares_1996.pdf $>$.

ABEPSS. Insumos para a crítica do Sistema Nacional de Avaliação da Graduação: contribuições da Abepss para o debate: documento preliminar. Brasília, 2010a. Disponível em: <http://www.Abepss. org.br/avalicao_do_Ensino_Superior_Abepss_2010.pdf $>$.

ABEPSS. Política Nacional de Estágio da Associação Brasileira de Ensino e Pesquisa em Serviço Social - Abepss. Brasília, 2009b. Disponível em: <http://www.abepss.org.br/briefing/documentos/politica_nacional_estagio.pdf $>$.

ABEPSS. Relatório Final do XII Encontro Nacional de Pesquisadores em Serviço Social. Brasília, 2011. Mimeo.

ABEPSS. Resolução de Estabelecimento da Pré-Filiação, de 23 de novembro de 2009. Rio de Janeiro, 2009a. Disponível em: <http:// www.abepss.org.br/briefing/documentos/Proposta_de_Pr-Filiao. pdf $>$.

CONSELHO FEDERAL DE SERVIÇO SOCIAL (Brasil); ABEPSS. Relatório Final do Curso de Especialização Latu Sensu em Serviço Social: Direitos Sociais e Competências Profissionais. Brasília, abr. $2011 a$. Mimeo.

CONSELHO FEDERAL DE SERVIÇO SOCIAL (Brasil). Plano de Lutas em Defesa do Trabalho e da Formação e Contra a Precarização do Ensino Superior. Brasília: CFESS, GT trabalho e formação profissional, 28 maio 2011. Disponível em: <www.cfess.org.br/arquivos/ 
Plano-de-Lutas-atualizado-maio-2011.pdf >.

CONSELHO FEDERAL DE SERVIÇO SOCIAL (Brasil). Resolução CFESS $n^{\circ}$ 533, de 29 de setembro de 2008. Regulamenta a SUPERVISÃO DIRETA DE ESTÁGIO no Serviço Social. Brasília, 2008. Disponível em: < http://www.cfess.org.br/arquivos/Resoluca0533.pdf>.

SOBRE A INCOMPATIBILIDADE entre Graduação a distância e Serviço Social. Brasília: CFESS/CRESS/ABEPSS/ENESSO, 2011b. Disponível em: http://www.cfess.org.br/arquivos/01_sobreaincompatibilidade_2011.pdf

TEMPORALIS. Brasília: ABEPSS, ano 8, n. 15, jan./jun.2008.

TEMPORALIS. Brasília: ABEPSS, ano 8, n. 16, jul./dez. 2008.

TEMPORALIS. Brasília: ABEPSS, ano 9, n. 17, jan./jun.2009. 